\title{
Determination of Candesartan and Hydrochlorothiazide in Human Plasma by HPLC Coupled with Mass Spectrometry
}

\author{
Olga S. Brushinina*, Roman V. Gurto, Maksim S. Timofeev, Galina A. Frelikh, \\ Vladimir A. Slepichev, Elena A. Yanovskaya, Natalia U. Polomeeva, Yulya G. Zyuz'kova, \\ Vladimir V. Udut \\ Federal Governmental Budgetary Institution "Research Institute of Pharmacology E.D. Goldberg's Name" \\ Siberian Branch of the Russian Academy of Medical Sciences, Tomsk, Russia \\ Email: olga.brushinina@pharmso.ru, roman.gurto@pharmso.ru
}

Received 3 April 2014; revised 3 May 2014; accepted 2 June 2014

Copyright (C) 2014 by authors and Scientific Research Publishing Inc.

This work is licensed under the Creative Commons Attribution International License (CC BY). http://creativecommons.org/licenses/by/4.0/

\section{(c) (i) Open Access}

\begin{abstract}
Quantitative determination of hydrochlorothiazide (HCTZ) and candesartan (CDS) in human plasma in volunteers was performed using a sensitive, selective and specific LC-MS method which has been developed and validated before the study. The study was performed by means of a liquid chromatograph Shimadzu Prominence equipped with a mass spectrometer LCMS-2020. Analytical column PerfectBond ODS-HD HPLC-column $5 \mu \mathrm{m} 250 \times 3.0 \mathrm{~mm}$ with a pre-column cartridge PerfectBond ODS-HD $5 \mu \mathrm{m} 10 \times 3.0 \mathrm{~mm}$, double source of ionization for LCMS-2020 (electrospray (ESI) and chemical (APCI)) and software LabSol LCMS V5 LCMS2020 systempack were used. The low limit of the quantitative determination for HCTZ and CDS made up $10 \mathrm{ng} / \mathrm{ml}$. $\mathrm{m} / \mathrm{z}$ for CDS 441.20 - positive scan, $m / z$ for HCTZ 295.90 -negative scan. The method has been applied to a pharmacokinetic study of $12.5 \mathrm{mg} \mathrm{HCTZ}$ and $16 \mathrm{mg}$ CDS tablet in healthy volunteers.
\end{abstract}

\section{Keywords}

Candesartan, Hydrochlorothiazide, LC-MS, Pharmacokinetic

\section{Introduction}

HCTZ and CDS have been recently suggested as a combination therapy for the treatment of arterial hypertension [1]. HCTZ and CDS have an additive antihypertensive effect [2]. In clinical studies the rate of the devel-

\footnotetext{
*Corresponding author.
}

How to cite this paper: Brushinina, O.S., et al. (2014) Determination of Candesartan and Hydrochlorothiazide in Human Plasma by HPLC Coupled with Mass Spectrometry. International Journal of Analytical Mass Spectrometry and Chromatography, 2, 25-32. http://dx.doi.org/10.4236/ijamsc.2014.22003 
oped side effects, especially cough, on the background of simultaneous HCTZ and CDS application was lower than in case of therapy using inhibitors of angitensin converting enzyme and HCTZ application without CDS [3].

Efficacy of HCTZ/CDS combination does not depend on sex and age of patients [3].

Several methods have been reported for the determination of either HCTZ of CDS alone in human plasma with LC-MS [4] in combination with UV or fluorescence [5]. Taking into account the availability of the combined drug, the development of a simple, sensitive method seems to be rather topical for the simultaneous HCTZ and CDS determination in human plasma. Several methods have been reported for LS-MS/MS determination, however, the detectors are rather expensive and they are not available for a majority of clinical centers. LC-MS detectors are less expensive and can be applied in a clinic for conducting medicamentous monitoring [6]-[9].

There are many publications on the definition of HCTZ and CDS in biological samples. Most published studies have been based on the use of expensive equipment LC-MS/MS, which is not available for many clinical centers. There are also several works using fluorometric and photometric detectors. The lake of all existing methods is either the sample drying step or stage derivatization, which complicate the procedure of sample preparation and affect the reproducibility of the method.

This paper has been demonstrated a sensitive and selective HPLC-MS method for the quantitative assessment of CDS and HCTZ in plasma samples of healthy Russian volunteers. This method is comparable on the sensitive methods HPLS-MS/MS, and greatly facilitates specimen sample preparation which consists of one stage of the sample extraction without drying dryness that allows it to be used for routine analysis in clinical practice.

The present work reports a LC-MS method for the determination of HCTZ and CDS in human plasma.

\section{Experimental}

\subsection{Chemical and Reagents}

Working standards of CDS and HCTZ were provided by EDGM (Company identification: European Directorate for the Quality of Medicines \& Healthcare). Medical drugs-tablets containing $12.5 \mathrm{mg} \mathrm{HCTZ}$ and $16 \mathrm{mg}$ CDS drug Atakand Plus (Astra Zeneka AB, Sweden). HPLC: acetonitrile was purchased from the firm SPC "Cryochrom", ethylacetate CP (chemically pure) and formic acid PFA (pure for analyses). All reagents were used without further purification. Blank human plasma was obtained from the blood bank and stored at $-20^{\circ} \mathrm{C}$ prior to use. Water was purified using a Milli-Q reagent Grade Water System.

\subsection{Instrumentation}

The LC-MS system consisted of a high performance liquid chromatograph equipped with a mass spectrometer (Shimadzu LC-MS-2020) with a double source of ionization for LCMS-2020 (electrospray (ESI) and chemical (APCI)), software LabSol LCMS V5 LCMS 2020 systempack.

\subsection{LC-MS Chromatographic Conditions}

Chromatographic separation was performed using a high pressure pump with a double micro-plunger mechanism for feeding the mobile phase Shimadzu LC-20AD, an autoinjector Shimadzu SIL-20A with a mechanism of direct sample unit, an analytical column PerfectBond ODS-HD HPLC-column $5 \mathrm{~mm} 250 \times 3.0 \mathrm{~mm}$ with a pre-column cartridge PerfectBond ODS-HD guardcartriges $5 \mathrm{~mm} 10 \times 3.0$, a thermostat of columns Shimadzu CTO-20A. The mobile phase was an acetonitrile solution with formic acid $(0.3 \%)(70: 30 \mathrm{v} / \mathrm{v})$. The separation was performed under gradient conditions. $m / z$ for CDS 441.20 —positive scan, $m / z$ for HCTZ 295.90—negative scan. Chromatographic characteristics of the method of analysis are listed in Table 1.

\subsection{Standard Solutions and Calibrators}

Stock standard solutions of CDS and HCTZ ((1 mg/mL) each in acetonitrile) were freshly prepared. A series of working standard solutions were diluted in acetonitrile to produce eight standard solutions ranging $10-250$ (ng/mL) for CDS and $10-150(\mathrm{ng} / \mathrm{mL})$ for HCTZ, respectively. Matrix based calibrators were prepared by spiking $100 \mu \mathrm{L}$ of each standard solution to a final volume of $1.00 \mathrm{~mL}$ plasma. Quality control samples were prepared at 10, 30, 120, 200 and $250(\mathrm{ng} / \mathrm{mL})$ for CDS and 10, 30, 60, 100 and 150 (ng/mL) for HCTZ. Plasma solutions were stored in subdued light at $-20^{\circ} \mathrm{C}$ until assay. 
Table 1. Chromatographic characteristics of the method of analysis.

\begin{tabular}{ccc}
\hline Parameter & CDS & HCTZ \\
\hline Retention time, min & $6.3-6.5$ & $5.4-5.6$ \\
LLQD, ng/ml & 10 & 10 \\
Signal/Noise & 8.4 & 5.8 \\
Linearity, ng/ml & $10-250$ & $10-150$ \\
\hline
\end{tabular}

\subsection{Sample Preparation}

To determine the HCTZ concentration in human plasma the obtained samples were thawed at room temperature. To an aliquot of $500 \mu \mathrm{L}$ plasma in a tube with a tight cap, $1000 \mu \mathrm{L}$ volume of ethyl acetate was added, mixed thoroughly for 1 minute, then the tubes were centrifuged at $3000 \mathrm{rpm}$ for 10 minutes. The residue was chosen, filtrated using filters Millipore with a pore diameter of $0.22 \mu \mathrm{m}$, placed to the vials with a tight cap. A $10 \mu \mathrm{L}$ aliquot of the solution was used for the chromatographic analyses.

To determine the CDS concentration in human plasma, the obtained samples were thawed at room temperature. To an aliquot of $250 \mu \mathrm{L}$ plasma and $250 \mu \mathrm{L}$ volume of $0.5 \%$ formic acid solution, $1000 \mu \mathrm{L}$ volume of ethyl acetate was added in a tube with a tight cap, mixed thoroughly for 1 minute, then the tubes were centrifuged at $3000 \mathrm{rpm}$ for 10 minutes. The residue was chosen, filtrated using filters Millipore with a pore diameter of 0.22 $\mu \mathrm{m}$, placed to the vials with a tight cap. A $10 \mu \mathrm{L}$ aliquot of the solution was used for the chromatographic analyses.

\subsection{Method Validation}

The method for the determination of CDS and HCTZ was been validated. Selectivity, accuracy, precision, limit of quantitation, linearity, recovery and stability were investigated during the pre-study validation phase.

\section{Results and Discussion}

\subsection{Mass Spectrometry}

An LC-MS system has been employed for the simultaneous determination of CDS and HCTZ in human plasma. Shimadzu LCMS-2020 offered high sensitivity and selectivity. $\mathrm{m} / \mathrm{z}$ for CDS 441.20 -positive scan, $\mathrm{m} / \mathrm{z}$ for HCTZ 295.90 - negative scan. The mass spectra for CDS and HCTZ are listed in Figure 1 and Figure 2, respectively.

\subsection{Chomatography}

Chromatographic separation was performed using an analytical PerfectBond ODS-HD HPLC-column $5 \mathrm{~mm} 250$ $\times 3.0 \mathrm{~mm}$ with a pre-column cartridge PerfectBond ODS-HD guardcartriges $5 \mathrm{~mm} 10 \times 3.0$, a thermostat of columns Shimadzu CTO-20A. The mobile phase was an acetonitrile solution with formic acid $(0.3 \%)$ (70:30 $\mathrm{v} / \mathrm{v}$ ). The flour rate was $0.2 \mathrm{ml} / \mathrm{min}$. The quantitative determination was performed by the method of the peak areas ratio. Retention time for CDS is 6.3 - 6.5 minutes, for HCTZ is 5.4 - 5.6 minutes.

\subsection{Method Validation}

\subsubsection{Intra-Day and Inter-Day Precision and Accuracy}

Evaluation of intra-day precision and accuracy was performed by the analysis of several sample preparations with different concentrations of CDS and HCTZ in human plasma, by 6 control samples on the low level of the quantitative determination (LLQD) as well as by 6 control samples with low (QD1), medium (QD2) and high (QD3) concentrations. Intra-day \% against nominal concentrations was in the ranges of 95.59\% - 104.17\%. Intra-day coefficients of variations were in the ranges of $2.41 \%$ and $10.93 \%$ and $3.0 \%$ and $8.1 \%$ for HCTZ. The results are listed in Table 2. Inter-day coefficients of variation were in the range of $4.64 \%-7.18 \%$ for CDS and $3.5 \%-10.8 \%$ for HCTZ. Inter-day \% against nominal concentrations was in the range of $99.19 \%-103.35 \%$. The data are given in Table 3. 


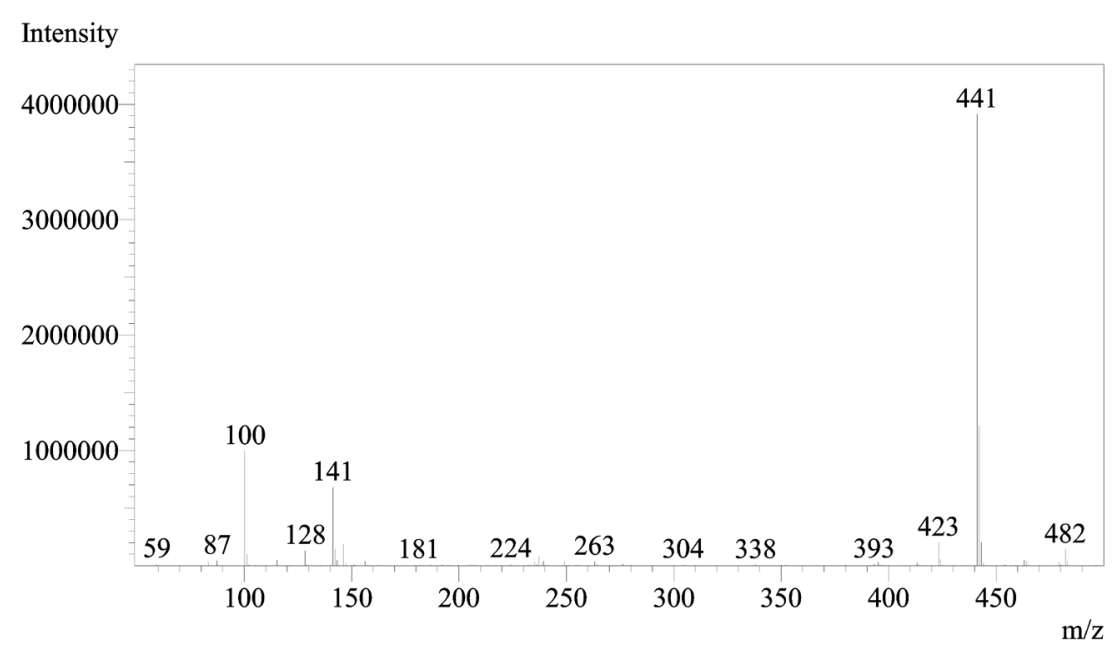

Figure 1. Mass spectra for CDS (CDS positive scan).

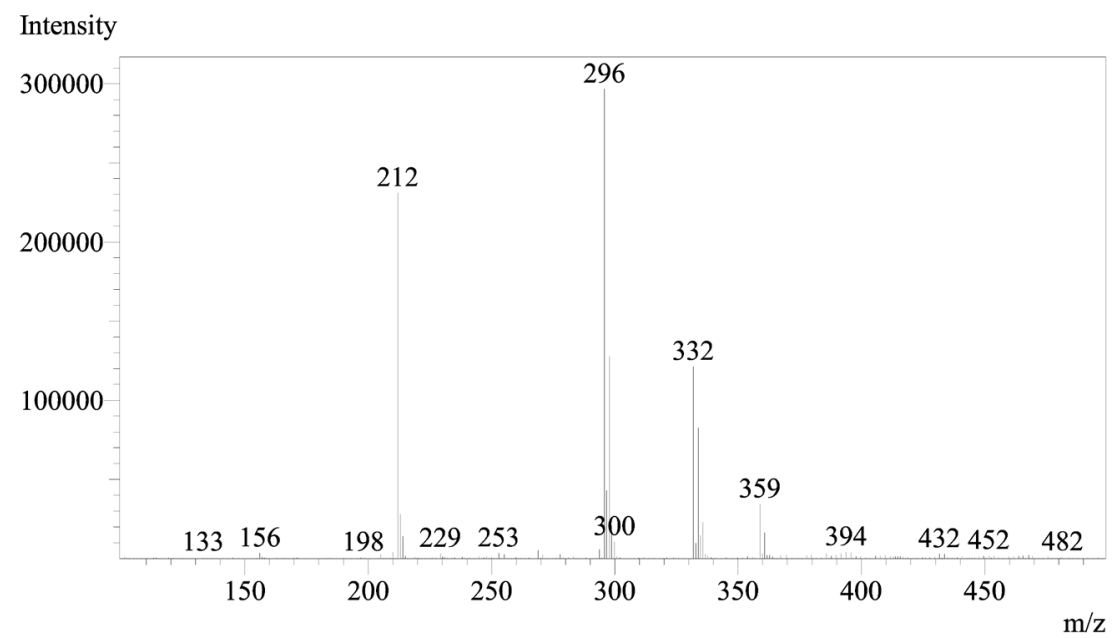

Figure 2. Mass spectra for HCTZ (HCTZ negative scan).

Table 2. Intra-day.

\begin{tabular}{ccccc}
\hline & \multicolumn{2}{c}{ CDS } & \multicolumn{2}{c}{ HCTZ } \\
\cline { 2 - 5 } & Accuracy, \% & Precision (CV), \% & Accuracy, \% & Precision (CV), \% \\
\hline LLQD & 103.38 & 10.9 & 99.5 & 6.4 \\
QD1 & 95.59 & 9.1 & 103.01 & 8.4 \\
QD2 & 104.17 & 2.4 & 99.3 & 3.2 \\
QD3 & 97.62 & 5.0 & 96.91 & 3.0 \\
\hline
\end{tabular}

Table 3. Inter-day.

\begin{tabular}{ccccc} 
& \multicolumn{2}{c}{ CDS } & \multicolumn{2}{c}{ HCTZ } \\
\cline { 2 - 5 } & Accuracy, \% & Precision (CV), \% & Accuracy, \% & Precision (CV), \% \\
\hline QD1 & 102.35 & 7.2 & 103.09 & 6.0 \\
QD2 & 100.94 & 4.9 & 99.86 & 3.5 \\
QD3 & 99.19 & 4.6 & 103.31 & 10.8 \\
\hline
\end{tabular}




\subsubsection{Recovery}

Absolute recovery of CDS and HCTZ was evaluated by comparing the medium areas obtained from six extracted plasma standards from with QD1, QD2 and QD3 concentration with medium areas from six standards in the mobile phase. The mean absolute recovery of CDS in the standards was $85.27 \%$, $91.63 \%$ and $77.82 \%$ for low, medium and high concentration, respectively. The mean absolute recovery for HCTZ was 50.47\%, 60.41\% and 66.44\%, respectively. The results are given in Table 4.

\subsubsection{Linearity, Linear Working Range and Calibration Models}

The quantitative determination of CDS and HCTZ was performed using the method of external standardization. The calibration graph plotted by adding the available concentration of CDS and HCTZ to the intact human plasma a subsequent determination of the peak areas is described by the linear function $\mathrm{y}=(200.876) \mathrm{x}-$ 125.595 (the correlation coefficient of 0.976 ) for HCTZ and $y=(448.517) x-608.977$ (the correlation coefficient of 0.987 ) for CDS where $\mathrm{x}$ is a meaning of concentration; $\mathrm{y}$ is a peak area. Response functions from calibrators were recorded individually for CDS and HCTZ. Each was plotted against the corresponding concentrations in the dynamic ranges of $10-250(\mathrm{ng} / \mathrm{ml})$ for CDS and $10-150(\mathrm{ng} / \mathrm{ml})$ for HCTZ. Representative calibration curves for CDS and HCTZ in human plasma are given in Figure 3 and Figure 4, respectively.

Table 4. Recovery.

\begin{tabular}{lcc}
\hline & CDS & HCTZ \\
\cline { 2 - 3 } & $\mathrm{R}, \%$ & $\mathrm{R}, \%$ \\
\hline QD1 & 85.27 & 50.47 \\
QD2 & 91.63 & 60.41 \\
QD3 & 77.82 & 66.44 \\
\hline
\end{tabular}

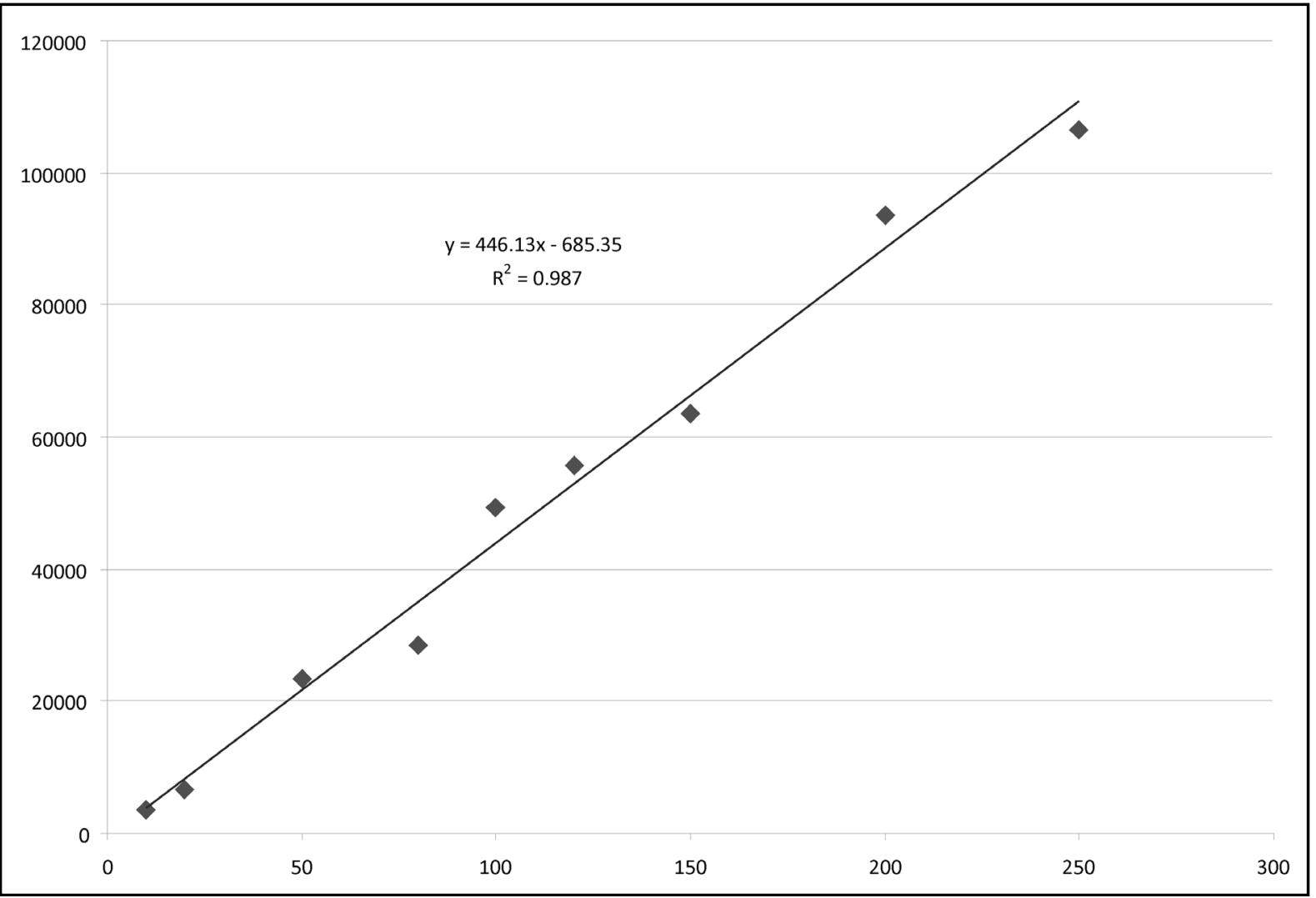

Figure 3. Representative calibration curves for CDS in human plasma. 


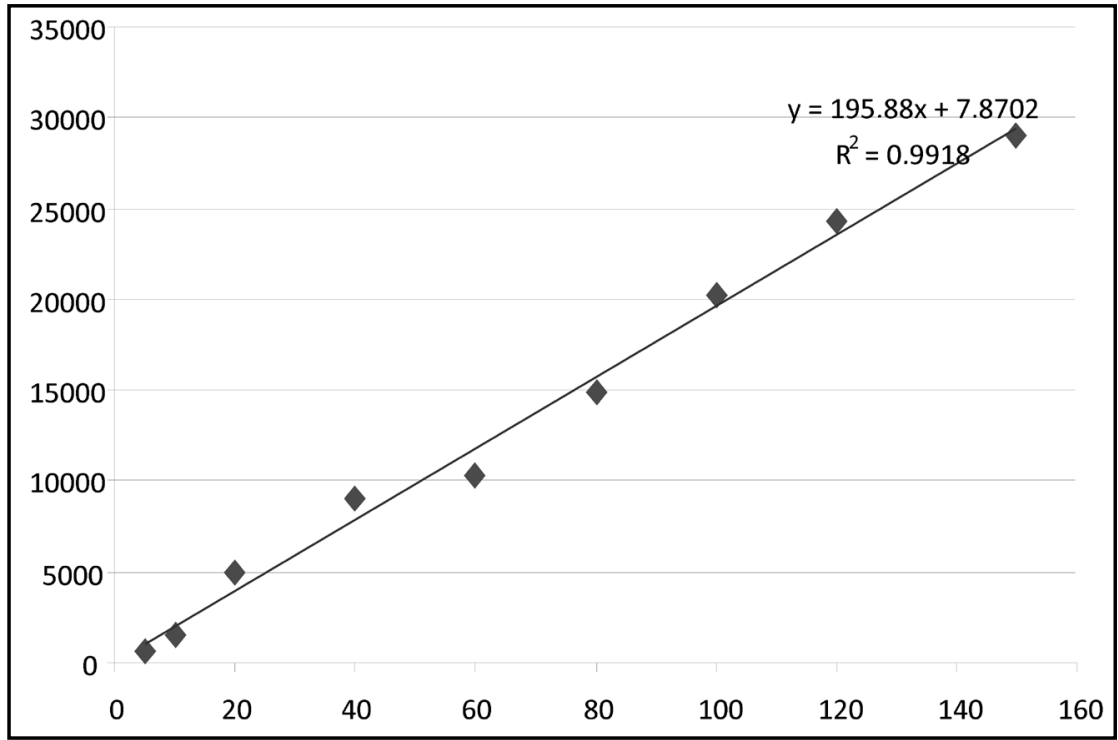

Figure 4. Representative calibration curves for HCTZ in human plasma.

\subsubsection{Low Level of the Quantitative Determination}

LLQD, i.e. the low level of the standard with a coefficient of variation of less than $20 \%$ makes up $10 \mathrm{ng} / \mathrm{ml}$ with a coefficient of variation of $17.68 \%$ and $\%$ against the nominal concentration of $86.52 \%$ for HCTZ and $10.93 \%$ and $\%$ against the nominal concentration of $103.4 \%$ for CDS. Evaluation of the signal/noise ratio of LLQD was performed by comparing the medium analyte response in six processed samples of the calibration standard (CS1) with the least concentration and the mean level of noise on zero level at about retention time for analyte in six preparations of a blank sample of matrix. LLQD should demonstrate the ratio of signal/noise $\geq 5$. LLQD HCTZ makes up $10 \mathrm{ng} / \mathrm{ml}$ with signal/noise ratio $=5.8$. LLQD CDS makes up $10 \mathrm{ng} / \mathrm{ml}$ the ratio signal $/$ noise $=8.4$. The results are given in Table 5.

\subsubsection{Stability}

Short-term stability of an analyte in matrix was analyzed at room temperature. The samples were prepared on the level of control samples with QD1 and QD3 concentration. CDS and HCTZ were considered to be stable in human plasma over $24 \mathrm{~h}$ at room temperature after sample processing with a \% change by $-2.73 \%$ and $2.92 \%$ for QD1 and QD3, respectively, for CDS and with a \% change by $-1.77 \%$ and $-10.16 \%$ for QD1 and QD3, respectively, for HCTZ. The results are given in Table 6.

Long-term stability of an analyte was studied at $-30^{\circ} \mathrm{C}$. With a \% change by $1.02 \%$ and $7.56 \%$ for QD1 and QD3, respectively, for CDS and with a \% change by $-1.22 \%$ and $-11.82 \%$ for QD1 and QD3, respectively, for HCTZ. The data are given in Table 7.

\section{Application: Pharmacokinetic Study}

The validated bioanalytical method was successfully applied for the determination of plasma concentrations of CDS and HCTZ in a pharmacokinetic study in 36 healthy male volunteers, who received a tablet containing 16 mg CDS and $12.5 \mathrm{mg}$ HCTZ in a fasted state. Venous blood samples $(5 \mathrm{~mL})$ were collected into heparinized tubes at the following time points: immediately before dose administration $(0.00)$ and at, $0.50,1.00,1.33,1.67$, 2.0, 2.25, 2.50, 3.00, 3.50, 4.00, 4.50, 5.00, 6.00, 8.00, 12.0, 16.0, 24.0, 36.0 and $48.0 \mathrm{~h}$ after dosing. Blood samples were centrifuged ( $3000 \mathrm{rpm}$ for $10 \mathrm{~min}$ ); plasma was separated and stored at $-30^{\circ} \mathrm{C}$ until assay. The mean pharmacokinetic profiles are illustrated in Figure 5, Figure 6 whereas the pharmacokinetic parameters of $\mathrm{C}_{\max }, \mathrm{T}_{\max }, \mathrm{T}_{1 / 2}, \mathrm{AUC}_{0-48 \mathrm{~h}}$, and $\mathrm{AUC}_{0-\infty}$ are summarized in Table 8.

\section{Conclusions}

Selective, sensitive, precise and accurate LC-MS method for the simultaneous determination of CDS and HCTZ 
Table 5. LLQD.

\begin{tabular}{ccc}
\hline & CDS & HCTZ \\
\hline Concentration, ng/ml & 10 & 10 \\
Precision (CV), \% & 10.93 & 17.68 \\
Accuracy, \% & 103.4 & 86.52 \\
Signal/Noise & 8.4 & 5.8 \\
\hline
\end{tabular}

Table 6. Short-term stability.

\begin{tabular}{ccc}
\hline & CDS & HCTZ \\
\hline QD1, \% & -2.73 & -1.77 \\
QD3, \% & 2.92 & -10.16 \\
\hline
\end{tabular}

Table 7. Long-term stability.

\begin{tabular}{ccc}
\hline & CDS & HCTZ \\
\hline QD1, \% & 1.02 & -1.22 \\
QD3, \% & 7.56 & -11.82 \\
\hline
\end{tabular}

Table 8. Pharmacokinetic parameters.

\begin{tabular}{ccc}
\hline Parameter & CDS & HCTZ \\
\hline $\mathrm{T}_{\max }, \mathrm{h}$ & $3.69 \pm 0.55$ & $1.81 \pm 0.45$ \\
$\mathrm{C}_{\max }, \mathrm{ng} / \mathrm{ml}$ & $130.5 \pm 15.47$ & $136.91 \pm 51.70$ \\
$\mathrm{AUC}_{0-\mathrm{t}}, \mathrm{ng} * \mathrm{~h} / \mathrm{ml}$ & $1749.0 \pm 213.7$ & $812.19 \pm 317.55$ \\
$\mathrm{C}_{\max } / \mathrm{AUC}_{0-\mathrm{t}}$ & $0.0756 \pm 0.0122$ & $0.1719 \pm 0.0315$ \\
MRT, h & $15.46 \pm 1.60$ & $6.27 \pm 0.51$ \\
\hline
\end{tabular}

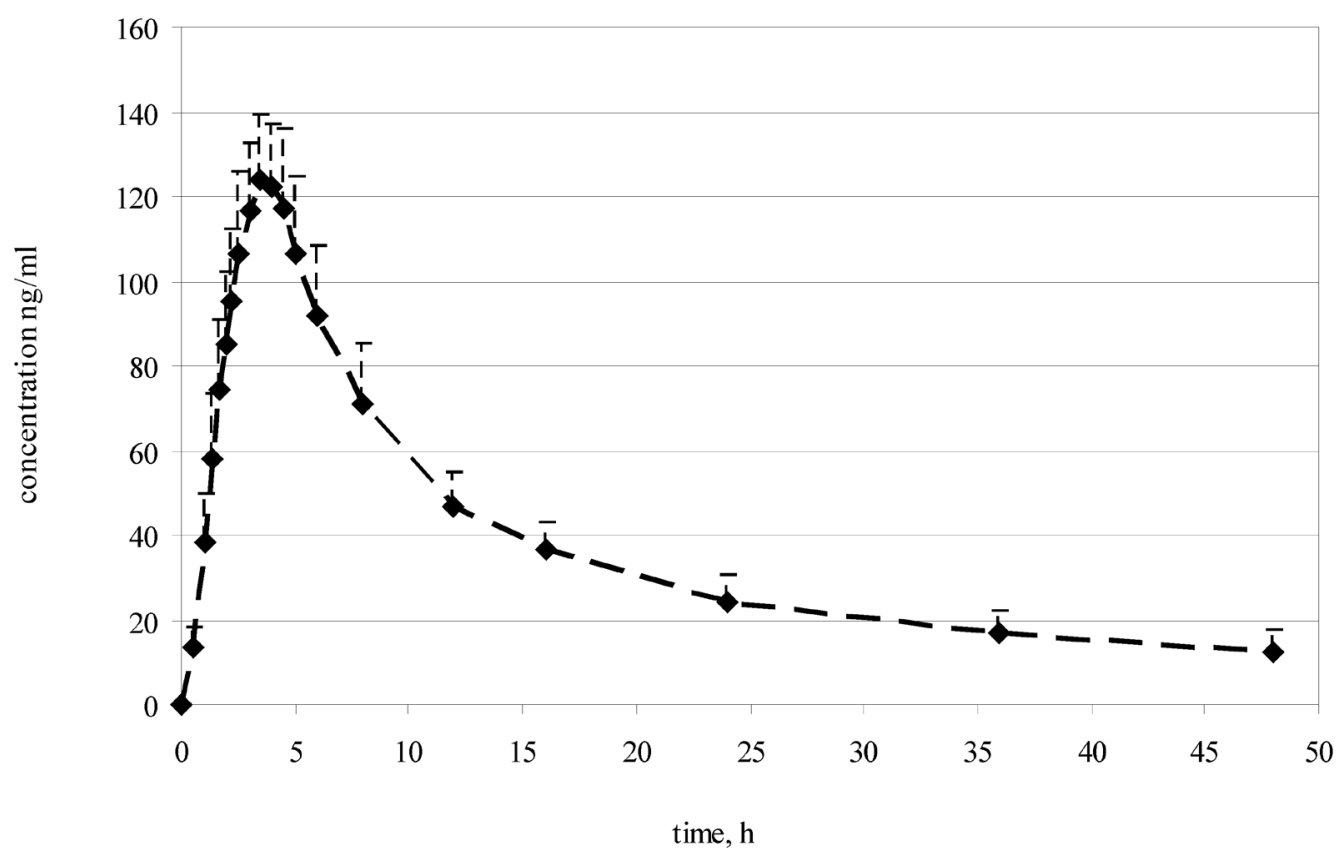

Figure 5. The mean pharmacokinetic profiles CDS in human plasma. 


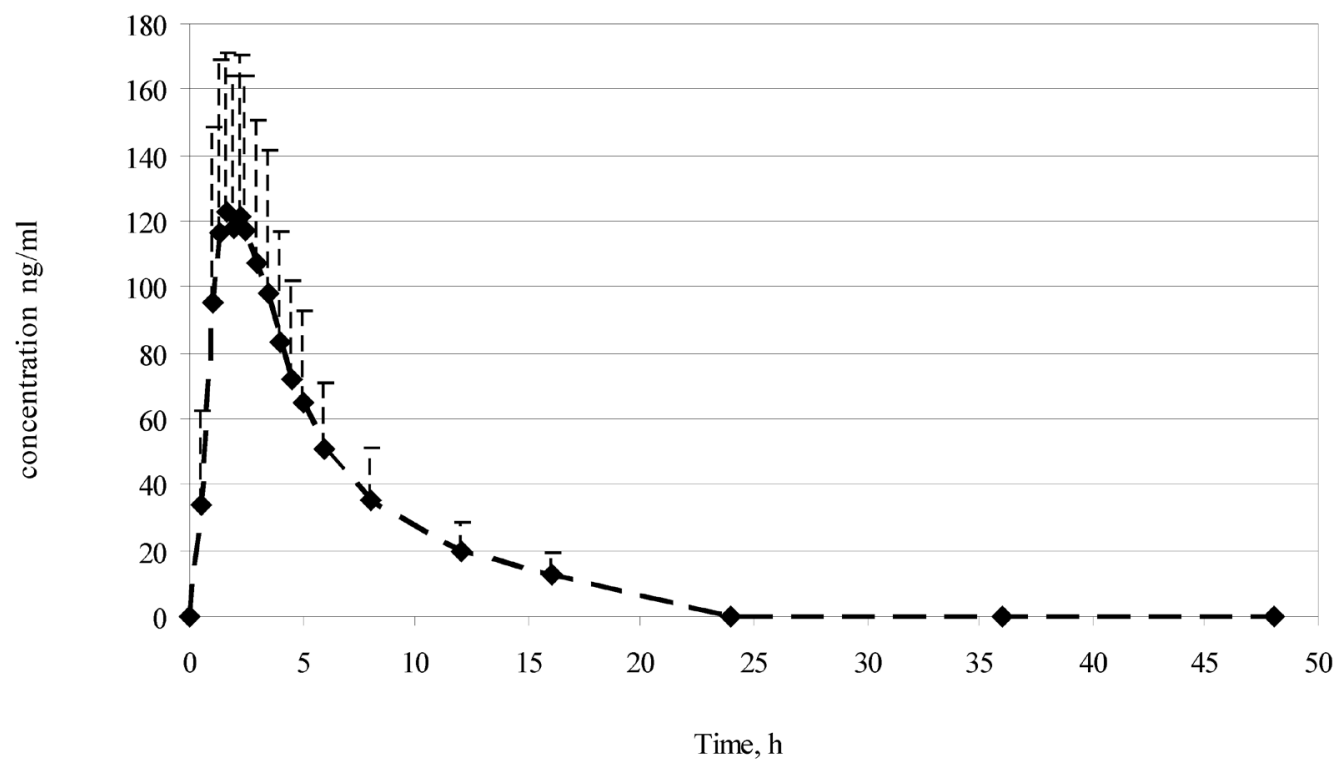

Figure 6. The mean pharmacokinetic profiles HCTZ in human plasma.

in human plasma has been developed, optimized and validated. A limit of quantitation $10 \mathrm{ng} / \mathrm{mL}$ for CDS and HCTZ enabled an accurate evaluation of pharmacokinetic parameters after dosing with CDS and HCTZ. The method has been successfully applied to the pharmacokinetic study of $16 \mathrm{mg}$ CDS and $12.5 \mathrm{mg}$ HCTZ tablet in healthy volunteers.

Thus, developed and validated HPLC-MS method of estimating the concentration of CDS and HCTZ in human blood plasma, can be used for therapeutic drug monitoring and bioequivalence studies.

\section{References}

[1] Gupta, A.K., Arshad, S. and Poulter, N.R. (2010) Compliance, Safety, and Effectiveness of Fixed-Dose Combinations of Antihypertensive Agents. Hypertension, 55, 399-407.

[2] Hernández-Hernández, R., Sosa-Canache, B., Velasco, M., Armas-Hernández, M.J., Armas-Padilla, M.C. and Cammarata, R. (2002) Angiotensin II Receptor Antagonists Role in Arterial Hypertension. Journal of Human Hypertension, 16, 93-99. http://dx.doi.org/10.1038/sj.jhh.1001352

[3] Unger, T. (2003) Blood Pressure Lowering and Rennin Angiotensin System Blockade. Hypertension, 21, 3-7. http://dx.doi.org/10.1097/00004872-200307006-00002

[4] Vetuschi, C., Giannandrea, A., Carlucci, G. and Mazzeo, P. (2005) Determination of Hydrochlorothiazide and Irbesartan in Pharmaceuticals by Fourth-Order UV Derivative Spectrophotometry. Farmaco, 60, 665-670. http://dx.doi.org/10.1016/j.farmac.2005.04.013

[5] Tu, J.H., Zhu, Y.B. and Xiao, D.W. (2008) Determination of Candesartan in Human Plasma by HPLC with Fluorescence. China Pharmaceuticals, 5, 48-49.

[6] Singh, B., Lokhandae, R.S., Dwivedi, A., Sharma, S. and Dubey, N. (2014) Improved Simultaneous Quantitation of Candesartan and Hydrochlorthiazide in Human Plasma by UPLC-MS/MS and Its Application in Bioequivalence Studies. Journal of Pharmaceutical Analysis, 4, 144-152.

[7] Gao, F., Zhang, M.L., Cui, X.Y., Wang, Z.H., Sun, Y.T. and Gu, J.K. (2010) Simultaneous Quantitation of Hydrochlorothiazide and Metoprolol in Human Plasma by Liquid Chromatography-Tandem Mass Spectrometry. Journal of Pharmaceutical and Biomedical Analysis, 52, 149-154. http://dx.doi.org/10.1016/j.jpba.2009.12.012

[8] Ramakrishna, N.V., Vishwottam, K.N. and Manoj, S. (2005) Sensitive Liquid Chromatography-Tandem Mass Spectrometry Method for Quantification of Hydrochlorothiazide in Human Plasma. Biomedical Chromatography, 19, 751760. http://dx.doi.org/10.1002/bmc.510

[9] Zendelovska, D., Stafilov, T. and Milosevski, P. (2004) Development of Solid-Phase Extraction Method and Its Application for Determination of Hydrochlorothiazide in Human Plasma Using HPLC. Biomedical Chromatography, 18, 71-76. http://dx.doi.org/10.1002/bmc.293 
Scientific Research Publishing (SCIRP) is one of the largest Open Access journal publishers. It is currently publishing more than 200 open access, online, peer-reviewed journals covering a wide range of academic disciplines. SCIRP serves the worldwide academic communities and contributes to the progress and application of science with its publication.

Other selected journals from SCIRP are listed as below. Submit your manuscript to us via either submit@scirp.org or Online Submission Portal.
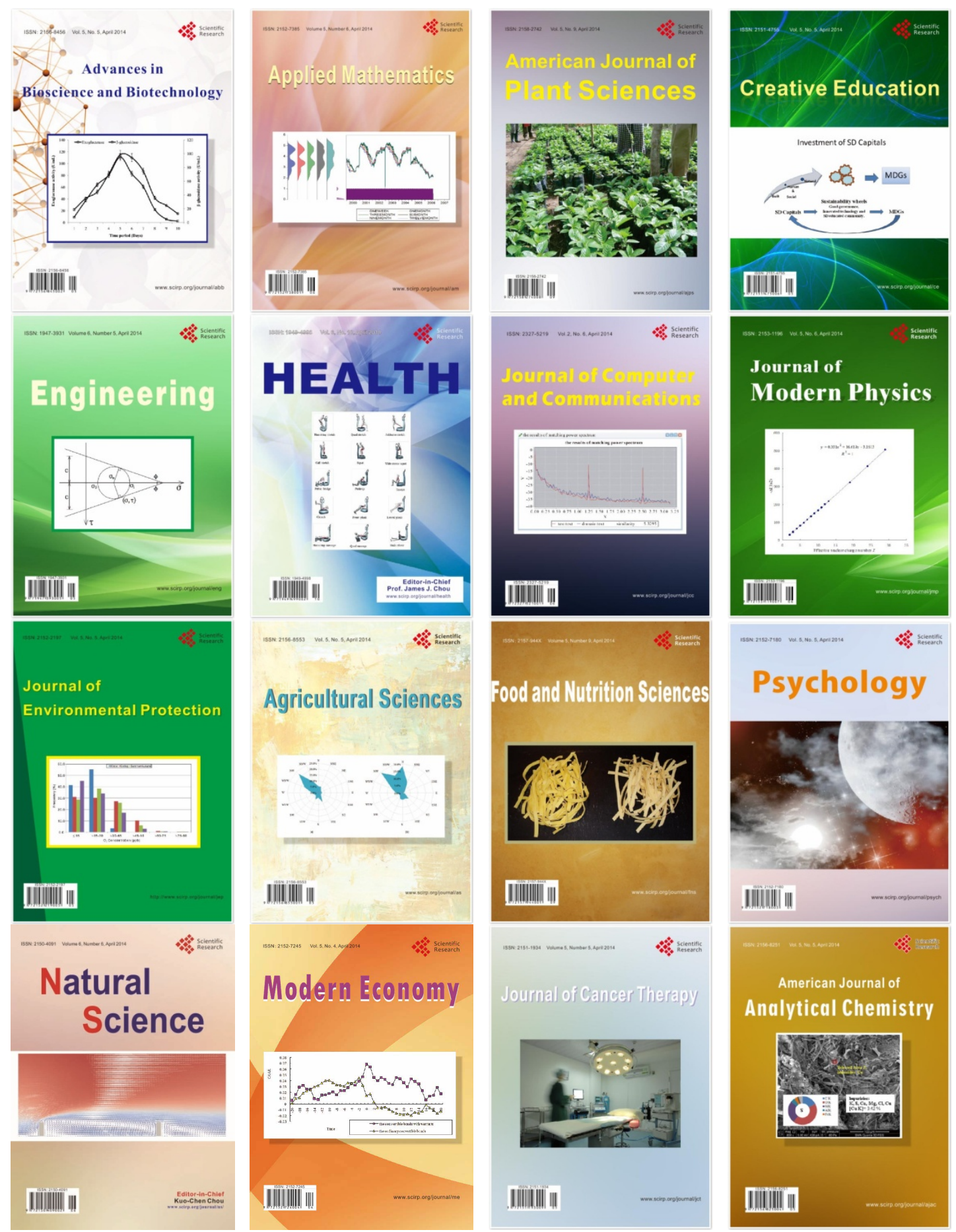